\title{
A MULHER E A FAMÍLIA NA HISTORIOGRAFIA LATINO-AMERICANA RECENTE
}

Eni de Mesquita Samara

(Universidade de São Paulo-USP/Brasil)

\section{1 - INTRODUÇÃO}

A historiografia das ultimas décadas, sem dúvida, favorece uma História Social da Mulher e da Família, preocupada com a análise e a percepção de processos históricos antes considerados de menor importância para o entendimento da natureza das sociedades.

A diversificação temática e a mudança dos focos de atenção do pesquisador enriqueceram os estudos historicos propiciando a incorporação de novos corpos de reflexão àqueles já consagrados. Assim, o cotidiano, os marginalizados, a mulher e a famflia ganharam espaço e dimensão nova nas interpretações recentes.

Nesse conjunto, especialmente no cenário internacional, os estudos dedicados à condição feminina e à família definiram linhas novas de pesquisa que resultaram em inúmeras publicações. Concretizaram também um sonho antigo á definir a criação dos Women's Studies e dos Grupos Interdisciplinares de Trabalho em diferentes centros europeus e norte-americanos. 
Se de início a historia da famflia e da mulher estiveram atreladas, em linhas gerais, ao desenvolver dos estudos de Demografia Histórica, hoje passados quase 30 anos, podemos dizer que aparecem como campos específicos de análise, embora complementares e sempre de caráter interdisciplinar.

Diante desse novo perfil e do volume da produção temática é quase impossível tratar esses dois aspectos, Mulher e Famulia conjuntamente. Por isso, optamos nessa ocasião por fazer uma apresentação em dois momentos, ou seja, em primeiro lugar analisando o tratamento dado à Historia das Mulheres na historiografia latino-americana recente, para depois verificarmos a questão na perspectiva da Historia da Familia.

\section{2 - A HISTÓRIA DAS MULHERES}

"Na Historia e no presente, a questão do poder esta no centro das relações entre homens e mulheres".

(Michelle Perrot)

Ao se pensar a "História de Mulheres", um repasse pela literatura das últimas decádas mostra que é impossível cobrir todas as vertentes e explorar a riqueza de possibilidades oferecidas para a análise historiográfica.

Especialmente a partir dos anos 70 , a produção cresceu e tomou vigor pluralista no seu sentido mais amplo de abordagens e conteúdos. Para essa verificação, basta recorrer às inúmeras bibliografias especializadas e números especiais de revistas que surgiram recentemente. ${ }^{1}$

Nesse conjunto, a questão do poder e da mulher, enquanto sujeito ativo da História, mereceu, em função da importância da problemática, um tratamento especial. Partindo de um viés aparentemente único, 
são múltiplas as interpretações de conteúdo histórico, e esse "paper" pretende enveredar por esse recorte, percorrendo uma parcela dos trabalho nos últimos vinte anos e que se referem à América Latina.

\section{1 - PODER, PODERES E MITOS}

A leitura de autores que estudaram as mulheres nas sociedades ocidentais e mais especificamente nas áreas de cultura ibérica, desvendam várias imagens de representação de poder ou de "poderes" por trás do trono, forças da sombra no discurso misógino. Rainha da noite, opõe-se ao homem diurno, digno de exemplo da ordem e da razão lúcida. ${ }^{2}$

Nos séculos XVI, XVII e XVIII a conviçãa da inferioridade intelectual feminina é nítida na literatura e na correspondência. Ao "sexo frágil", ao menos na aparência não havia como argumentar sobre a questão da igualdade de direitos.

Nos discursos dos "machistas" ibéricos são perigosas, tagarelas e comprovadamente incapazes. Em várias outras sociedades, os argumentos se repetem, em grau maior ou menor. ${ }^{3}$

É evidente que os pioneiros ibéricos transportaram para 0 ultramar a marca antifeminista, assimilável de forma vigorosa na sua cultura, em atitudes, comportamentos e valores.

Num primeiro momento, para as historiadoras dedicadas ao estudo da condição feminina no passado, essa questão aparece como um desafio, ou mesmo um desejo de recuperar a mulher na sua identidade social e de mostrar a sua presença no processo de tomada de decisões. Vejam-se, por exemplo, os trabalhos de SUSAN ROGERS sobre o mito da dominação masculina e os "poderes" femininos e de MICHELLE PERROT sobre a mulher popular rebelde, entre muitos outros. ${ }^{4}$

No caso da América Latina, ALIDA METCALF mostra que as pesquisas de historiadores, sociologos e antropólogos apontam para duas visões dramaticamente distintas. Uma delas, propõe que a criatura passiva, protegida e isolada, sugerida pelos estereótipos da mulher latina, não existia. Decidindo e gerenciando negócios, essa mulher, por vezes, tinha mais direitos que a anglo-saxônica do mesmo 
período. ${ }^{5}$ Relatos de situações nas colônias ibéricas, indicam que em alguns casos eram mais poderosas que os homens. ${ }^{6}$

A produção brasileira, enveredando por esse caminho, optou pela análise do casamento e da divisão de poderes e de incumbências entre os casais. O eixo de discussão reside na construção do estereótipo de submissão nas relações marido/esposa. Atitudes e comportamentos desviantes, queixas e tensões que resultaram em divórcio e separações, mostram o lado "obscuro" das relações entre os sexos. A idéia é justamente a de recuperar uma mulher mais ativa e participante, apontando para as variações nos padrões de comportamento. ${ }^{7}$

Rever imagens e revelar outras é romper com os enraizamentos impostos pela historiografia ao longo do tempo. Assim, de forma crítica, foram se integrando cenas distantes, perdidas no seu tempo. À mulher branca de elite, ociosa, deitada na rede a gritar com seus escravos coube recuar e ceder espaços a outras mulheres antes sem história. Viúvas que honraram a memória do marido, os bordados, os doces, a conversa com as negras, o cafuné e as visitas dominicais à Igreja, vão se somando aos testemunhos sobre mulheres trabalhadoras, mediadores e intermediárias nas atividades de comércio e de negócios.

Trabalhos como os de A.J.R. RUSSELL-WOOD foram pioneiros ao apontar para o tratamento estereotipado e a importância de se entender a condição feminina no contexto da sociedade colonial brasileira. ${ }^{8}$ KUSNESOF, SILVA DIAS e SAMARA,por sua vez, algum tempo depois, vão deparar com um número significativo de mulheres como chefes de domicílio na São Paulo do final do XVIII e inícios do XIX. No meio urbano, moviam-se com rapidez costureiras, lavadeiras, doceiras e quitandeiras que trabalhavam para o sustento de suas casas. ${ }^{9}$

A existência de evidências de que uma parcela de mulheres das camadas mais abastadas vivia entregando-se à indolência, gerou o contraponto a um outro quadro onde, comprovadamente, o sexo feminino tinha maior participação, à testa da família e dos negócios, contribuindo com recursos para a manutençã̃o da casa, o que sem dúvida aumentava a esfera de influência feminina.

A coexistência dessas duas alternativas é sugerida pelos autores, relacionados ao padrão de moralidade e ao processo de socialização que preparava a menina para o desempenho dos encargos domésti- 
$\cos .^{10}$ No cerne dessa questão está a discussão do papel dos sexos e dos espaços permitidos a permear os estudos feministas recentes.

\section{2 - UNIVERSO FEMININO, PÚBLICO E PRIVADO}

No resgate da memória feminina, as falas sobre o "silêncio dos arquivos", os "segredos dos sótãos", as "leituras das entrelinhas" dos documentos, vão aos poucos compondo as análises sobre 0 universo feminino e a sua inserção no público e no privado.

O mundo das mulheres e a vida doméstica, palco de luta e de articulação dos "micro-poderes" foi inúmeras vezes pesquisando.

SANDRA LAUDERDALE GRAHAM, ao penetrar no espaço doméstico do Rio de Janeiro entre 1860 e 1910, buscou o entendimento dos níveis de dominação e subordinação expressos nas relações entre criados e patrões. ${ }^{11}$

Sem dúvida, no século XIX como nos anteriores, cada sexo tinha a sua função, seu papel, suas tarefas, seus espaços e seus lugares. No discurso dos ofícios e na linguagem do trabalho a divisão de tarefas é também sexuada. ${ }^{12}$

Segundo PERROT, a concepção de uma economia doméstica feminina se desenha nos tratados do final do XVIII e início do XIX. Os discursos dessa época dirigiram-se exclusivamente à dona-de-casa. encarregada do lar, enquanto as obras equivalentes dos séculos XVII e XVIII falavam do "dono-de-casa" como um verdadeiro chefe de empresa rural. ${ }^{13}$

No meio urbano, o exercício de papéis informais, improvisados, servem para desmitificar o sistema patriarcal brasileiro e a rígida divisão de tarefas e incumbências, conforme se aprende do trabalho de MARIA ODILA LEITE DA SILVA DIAS. ${ }^{14}$

Por tradição e costumes, nas uniões legítimas, a divisão de incumbências entre os sexos, pelo menos na aparência, colocava o poder de decisão formal nas mãos do homem como provedor da mulher e dos filhos. Para a mulher restava o bom desempenho do governo doméstico e a assistência moral à família, fortalecendo os seus laços. Ambos preenchiam papéis de igual importância, mas desiguais no teor da responsabilidade. ${ }^{15}$ 
A casa e a rua, a ruptura de esferas de atuação complementares e nitidamente separadas foram analisadas pelos historiadores dedicados ao estudo da condição feminina, sob o prisma da ausência do homem ou da sua presença intermitente.

Em São Paulo, no século XIX, intervinham no espaço urbano e no vaivém constante das ruas, escravas ganhadeiras, pardas e brancas pobres dedicadas a pequenos negócios, agências e expedientes.

"Os próprios recenseamentos indicam que cerca de 35 a $40 \%$ das mulheres assumiam o papel de provedora do sustento de suas famílias; como chefes de fogo, declaravam viver do seu proprio trabalho" ${ }^{16}$

"Mulheres sem História", elos de uma memória possivel de ser reconstituída nos manuscritos e depoimentos do seu tempo, não raramente penetravam nos espaços masculinos.

Por outro lado, a história social das mulheres das classes dominantes está longe de ser uma história de clausura e de passividade, como se aprende do trabalho pioneiro de ANTONIO CANDIDO ${ }^{17}$ Muitas vezes, no entanto, comando e iniciativa foram considerados como atributos viris da personalidade feminina, o que significa que as mulheres raramente se apresentam como personagens historicas na sua individualidade. ${ }^{18}$

O conduzir das análises historiográficas, leva a planos distintos de apreensão e identificação do perfil social das mulheres.

De um lado, o discurso oficial e as normas prescritas no sistema da dominação e de outro o cotidiano das mediações dos papéis sociais continuamente improvisados. O belo e exemplar trabalho de MARIA ODILA LEITE DA SILVA DIAS busca essencialmente essa última reconstrução - "sempre relegado ao terreno das rotinas obscuras, o quotidiano tem se revelado na História Social como área de improvisação de papéis informais, novos e de potencialidade de conflitos e confrontos, onde se multiplicam formas peculiares de resistência e luta". ${ }^{19}$

Ainda no plano dos esterétipos, dos mitos e das imagens literárias a contradição nos papéis existe, mas é explicável em função do padrão duplo de moralidade que regulava as relações dos sexos e dos grupos sociais. ${ }^{20}$ 
No bojo da discussão sobre a alternância de papéis está a questão da identidade social das mulheres e do processo de socialização.

PERROT também se interroga sobre as atitudes das próprias mulheres quanto a sua inserção no plano político, enfatizando que são responsáveis em parte pelo processo de socialização e transmissão da cultura, consentindo em valorizar mais o social e o informal, interiorizando as normas tradicionais.

A construção dos grandes arquétipos e a mulher como transmissora da cultura estão muito presentes na literatura feminista das últimas décadas.

Nessa trilha estão trabalhos como os de EVELYN STEVENS que focaliza um aspecto crucial da condição feminina na América Latina, ou seja, de que o marianismo, culto da superioridade espiritual das mulheres, na realidade as transforma em beneficiárias conscientes desse mito. Conclui STEVENS também que o marianismo é parte de um arranjo recíproco e, portanto, a outra metade do machismo. ${ }^{21}$

A participação política da mulher, o acesso à cidadania e a questão dos direitos aparecem com frequência nas coletâneas dedicadas à América Latina.

Organizadas sob múltiplas perspectivas e de caráter indisciplinar, essas coletâneas, publicadas especialmente nos anos 70, mostraram um primeiro perfil de conjunto da condição feminina na América Latina

Reunindo trabalhos sobre diferentes países, avançaram no debate sobre as questões políticas e o papel das mulheres na família e na sociedade, apresentando também os primeiros balanços bibliográficos, principais tendências, temas e problemas de pesquisa.

A edição organizada por ASUNCIÓN LAVRIN é um típico exemplo dessas preocupações. ${ }^{22}$ No entanto, o pequeno número de análises sobre o Brasil, mostra que existe ainda uma lacuna a ser preenchida. Os ensaios específicos, salvo algumas exceções, versaram sobre temas já apresentados em outros artigos.

Especialmente interessante nesse conjunto é o estudo de JUNE HAHNER sobre A imprensa feminina no Brasil e os direitos das mulheres no século XIX, onde mostra que durante a segunda metade de século XIX algumas mulheres brasileiras avançaram em argumentos muito similares aos das feministas americanas. $\mathrm{O}$ trabalho se baseia 
em depoimentos encontrados nos jornais editados por mulheres e que apareceram em cidades do centro-sul do Brasil. Iniciando suas reclamações por educação e respeito pela mulher, algumas chegaram a clamar pelas mudanças do status legal e pelo direito de voto . HAHNER argumenta que esse jornais revelaram mudanças na posição ocupada e nas aspirações da mulher brasileira, além de um crescente grau de consciência. ${ }^{23}$

Outra coletânia, Female and male in Latin America, publicada nos anos 70, tem por objetivo fundamental o exame dos papéis e atitudes em relação à mulher na América Latina e o conflito entre a imagem e a realidade. Envolve também o estudo do processo de modernização e os conflitos com o tradicionalismo. ${ }^{24}$

Editado por ANN PESCATELLO, caracteriza-se por uma problematização mais profunda da questão feminina e do machismo, com uma conotação política mais presente.

Em imagens e realidades da vida da mulher, são construídos arquétipos a partir dos romances e das revistas. JANE. S. JAQUETTE, CORNÉLIA BUTLER FLORA e a própria organizadora, alternam-se na prática e no uso da literatura como fonte histórica. Nesse conjunto, o ensaio de PESCATELLO sobre "The brazileira: images and realities in writings of Machado de Assis e Jorge Amado" focaliza questões teoricas de importância fundamental. O pressuposto é que toda literatura fornece símbolos, estereótipos, arquétipos e papéis que são extremamente úteis para testar as situações reais. Assim, procura determinar e definir as realidades das brasileiras e as mudanças e continuidades que ocorreram na sua História nos séculos XIX e XX. ${ }^{25}$

Passado, presente, perspectivas históricas e futuras, compõem um conjunto de nove outros trabalhos sobre machismo, participação política da mulher, liberação feminina, atuação profissional e trabalho doméstico. Historiadores, antropólogos, cientistas políticos, sociólogos e psicólogos, ao analisar México, Argentina, Chile, Peru Colômbia, Brasil e Cuba buscam descortinar realidades mais próximas da vida das mulheres na América Latina e suas formas de participação ou exclusão dos processos em curso.

Ainda nessa linha, as biografias de mulheres notáveis surgidas recentemente, indicam que essa temática não foi abandonada. 
Certamente são uma forma de reunir experiências individuais de mulheres num cenário conjunto, tirando-as da esfera doméstica para posições de destaque na sociedade. Sob o prisma da inserção no espaço público, a abordagem biográfica e mais um recurso utilizado pelos pesquisares. Ten notable women of Latin America de JAMES D. HENDERSON \& LINDA HENDERSON é um exemplo de que essas questões ainda são investigadas. Mulheres fortes e participantes contrastam com imagens de fragilidade e de submissão típicas das narrativas literárias, das memórias dos relatos de viajantes e cronistas. ${ }^{26}$

Além das coletâneas de artigos e de biografias, às mulheres latinas dedicaram-se números especiais de revistas, onde a questão do poder, da mudança de status e do acesso à cidadania foram amplamente debatidos e contextualizados em função das diferenças regionais e temporais. ${ }^{27}$ Feminismo, reformas morais, direito de voto, mercado de trabalho e ações futuras de engajamento político são alguns dos temas tratados nessas edições. A recuperação do passado é parte das análises, na perspectiva do entendimento das rupturas e continuidades no complexo sistema de relações sociais, econômicas e políticas que compõem o panorama latino-americano.

Pelo que se pode perceber, a recuperação da história da participação política das mulheres, seus espaços e seus papéis, é um exercício a que se dedicaram inúmeros pesquisadores. Saindo das "salas de visitas", vasculhando os arquivos e desvendando os "segredos dos sótãos", o objetivo foi sempre o de documentar, ou de comprovar que é possível fazer a história das mulheres sob múltiplas facetas. Por isso, os contornos são vários e é impossível analisá-los nos seu conjunto completo.

Diante desse quadro, no entanto, ainda ficam lacunas, indagações e caminhos a percorrer, especialmente no que tange à rede de poder e às estrategias desenvolvidas pelas mulheres na ordem paternalista da sociedade latino americana. 


\section{3 - SUBORDINAÇÃO, REDE DE PODER E REVERSÃO DA ORDEM}

Estudiosos interessados no assunto evocam a rede de laços de dependência através dos quais os pobres buscavam a proteção dos ricos e a elite mantinha a ordem social. A subordinação da mulher ao homem é vista nesse contexto. Segundo METCALF,o viés de uma possível análise dessa situação é a relação entre mulher e propriedade, levando-se em conta as diferenças entre o meio rural e o urbano.

A autora avança a discussão sob o prisma dos ciclos familiares, mostrando que as mulheres só tinham acesso à propriedade a longo prazo e que esse acesso era controlado. Isto significa que as mulheres proprietárias não necessariamente tinham influência na família e na comunidade em geral, apesar dos direitos e garantias estabelecidas no Código Filipino e na Legislação Portuguesa. ${ }^{28}$

A gerência do patrimônio pelas viúvas e o dote visto na perspectiva de um certo privilegiamento das famílias perdem força na argumentação da autora. ${ }^{29}$

Enfim, permanece a questão e o desejo das historiadoras de desvendar a articulação das mulheres com a rede de poder.

SAFFIOTI, ao apropriar-se da discussão em $O$ poder do macho insere a mulher em um sistema mais amplo de dominação, ao analisar as diferentes formas de dominação e subordinação. Entende que sociedade não está dividida entre homens de um lado e mulheres subordinadas de outro. Há homens que dominam outros homens, mulheres que dominam outras mulheres e mulheres que dominam homens. Para SAFFIOTI, embora a sujeição feminina seja mais sensível e profunda que a masculina na sociedade brasileira, o patriarcado, definido como sistema de relações sociais que garante a subordinação da mulher ao homem, não constitui o único princípio estruturador da sociedade..$^{30}$

$\mathrm{Na}$ análise da condição feminina, ao nossso ver, as imagens as vezes são contraditórias e os estereótipos irreais. Estes últimos seriam apenas mitos? Existiu realmente o ideal da passividade feminina?

Alguns trechos da obra clássica de GILBERTO FREYRE acentuam ainda mais o paradoxo. $O$ autor sugere também que a 
preferência pela mulher submissa foi ditada pelo desejo do homem de eliminar a sua concorrência no jogo econômico e político. ${ }^{31}$

Segundo a literatura, o panorama é contraditório mas explicável em função do padrão de moralidade que regulava as relações dos sexos e dos grupos sociais. As mulheres de posses, em sua maioria, ficavam circunscritas às suas aspirações de casamento e filhos. Passavam dessa forma, da tutela do pai para o do marido e estavam menos expostas às relações ilíticas e, naturalmente mais aptas para desempenhar um papel tradicional e restrito. Aquelas das camadas mais pobres, mestiças, negras e mesmo brancas, viviam menos protegidas e sujeitas à exploração sexual. Suas relações se desenvolviam, portanto, dentro de um outro padrão de moralidade que, relacionado principalmente à dificuldades econômicas e de raça, contrapunha-se ao ideal vigente, mas não chegava a transformar a maneira pela qual a cultura dominante encarava a questão da virgindade e nem a posição privilegiada do sexo oposto. ${ }^{32}$

Outras vertentes, sob a ótica dos papéis informais vêem a sua inserção no espaço público de maneira ostensiva, embora institucionalmente e mesmo socialmente pouco valorizada. Apesar dos preconceitos e da desclassificação social, eram parte integrante do próprio sistema de dominação. $\mathrm{O}$ fato de não participarem da história política e administrativa, não diminui a importância do papel desempenhado, a exemplo dos segmentos sociais marginalizados..$^{33}$

Excluidas do "círculo do poder" souberam fazer a sua própria história.

Vista sob essa perspectiva, uma história da exclusão é, sem dúvida, palco de luta e de formas de articulação social. Na historiografia latino-americana recente, esse significado se traduz nas maneiras possíveis de se fazer a "Historia de Mulheres", que procuramos resgatar a partir da questão do poder.

\section{3 - NOVAS IMAGENS DA FAMÍLIA "À BRASILEIRA"}

Campo interdisciplinar de pesquisa e de reflexão, a família até bem pouco tempo pouca atenção mereceu dos historiadores. Temerosos no enfrentamento das análises clássicas sobre o assunto, contribur- 
ram com timidez, reforçando os modelos institucionais e os estudos genealógicos, usando o viés do poder para entender a importância da família na sociedade.

Se esse era o perfil da produção histórica antes dos anos 60 , essa década instaurou o debate e colocou o historiador diante dos velhos problemas com novas questões. Rompendo as barreiras específicas dos objetos de análise, os estudos históricos nos últimos 20 anos foram marcados pela diversificação temática.

A chamada "História Nova" propiciou maior enriquecimento das análises, mudanças dos focos de atenção e a incorporação de outros campos de reflexão àqueles já consagrados. Assim, o cotidiano, os segmentos marginalizados, a mulher, a família, a vida ítima e a sexualidade ganharam espaço e maior dimensão nas interpretações recentes.

Nesse quadro, a família adquiriu um papel fundamental, seguindo de perto as tendências de vanguarda, já que análise do tema possibilita uma revisão profunda na História Social do Brasil. A riqueza e o ineditismo das fontes primárias, associadas a pluralidade de assuntos que o tema aborda (mulher, criança, sexualidade, educação, etc) colocaram definitivamente a História da Família no Brasil, na década de 80 , como um ramo específico de conhecimento e de pesquisa, com área de atuação própria.

Reunir essa produção em seu conjunto e analisá-la não é uma tarefa fácil. Exige um grande esforço de localização de livros, teses defendidas, artigos, comunicações e textos ainda dispersos. ${ }^{34}$ Isso resulta da ampliação de pesquisas, organização de inúmeros eventos, seminários e publicações. ${ }^{35}$ Por outro lado, a timidez inicial dos historiadores de adentrarem por um campo antes praticamente limitado aos trabalhos de antropólogos, parece estar superada.

Nos rumos da historiografia brasileira recente, a redescoberta da família e a sua apropriação como objeto de análise, tem sentidos e significados próprios, claramente expressos no seu perfil.

$\mathrm{Na}$ década de 70, foram mais focalizados os aspectos referentes à estrutura da família, nupcialidade, fecundidade e equilibrio dos sexos, resgatados especialmente nos trabalhos dos demógrafoshistoriadores que utilizaram recenseamentos manuscritos da população e registros paroquiais. ${ }^{36}$ 
$O$ início de um processo de revisão dos grandes mitos e arquétipos sobre a sociedade brasileira do passado soma-se, nos anos 80 , as pesquisas sobre o papel dos sexos, o casamento, as uniões ilegítimas, o divórcio, as famílias dos segmentos expropriados (escravos e forros) e o processo de transmissão das fortunas. Nesse segundo momento é maior a pluralidade de assuntos. ${ }^{37}$ Inventários, testamentos, processos de separação de casais entre inúmeras outras fontes documentais, trazem à tona imagens veladas das relações entre os sexos e da vida familiar, que contrastam muitas vezes com o perfil típico da família brasileira tal como foi concebido pela literatura.

Enveredar por essa discussão, significa buscar os sentidos próprios das análises históricas recentes que pretendemos explorar a partir dos dados levantados sobre a família paulista no século XIX.

Divergências e similitudes com relação ao modelo genérico de família no Brasil, foram motivo de busca incessante na documentação manuscrita da época. Os resultados que se apresentaram, após anos de pesquisas, revelaram no entanto que é diffcil conceber uma imagem única e aplicável aos diferentes segmentos sociais nos vários momentos da nossa historia. ${ }^{38}$

No caso especffico da sociedade paulista, as descrições se desdobram numa realidade social multifacetada, mostrando que a sua população encontrou formas diferentes de organização e que valores normativos e ideologicos inerentes aos grupos dominantes nem sempre fizeram parte do cotidiano dos mais pobres, como poderemos ver a seguir.

\section{1 - ROMPENDO OS LAÇOS PATRIARCAIS: A FAMÍLIA PAULISTA}

Falar de família no Brasil implica necessariamente se remeter a uma formulação já clássica sobre o tema, que é a da família patriarcal que emerge na obra de Gilberto Freyre ${ }^{39}$ Além disso, a famflia é sempre lembrada como uma instituição que moldou os padrões da colonização e ditou as normas de conduta e de relações sociais. Isso sem dúvida, justifica um perfil de "brasilidade", associado à vida em família. 
"A estranha idéia de família viajando através da carne" do poema de Carlos Drummond de Andrade permanece, no entanto, misteriosa, mesmo para alguns brasileiros. Onde começa o mito e termina a realidade? Seria a família patriarcal apenas o resultado da construção de um grande arquétipo próprio das elites? Que outros modelos permitem identificar as estratégias matrimoniais? Seria essa família realmente extensa e organizada através do casamento ? Qual o papel do casamento e que parcela da população optava por uniões legítimas?

Por outro lado, a ênfase dada à família do tipo patriarcal ajudou a conceber a mito da mulher submissa e do marido dominador, que pode ser questionado através da análise do papel dos sexos, do casamento e do divórcio.

Enfim, penetrar no espaço sagrado da vida doméstica, no cotidiano das relações familiares, desvendar as tensões, os conflitos e os modelos de comportamentos é uma tarefa difícil, mas que apaixona e instiga.

Por isso, o historiador desenvolveu uma metodologia própria de análise, comparando as informações contidas na historiografia com as evidências empíricas encontradas nos documentos manuscritos dos séculos XVIII e XIX.

Nesse percurso são fundamentais os censos de população, os testamentos, os inventários e os processos de divórcio. Além deles é imprescindível recorrer a uma gama bastante variada de outrós documentos (descrições de viagens, memórias, ofícios), processos em geral (crimes, legitimações) e à legislação canônica e civil.

Esses documentos vistos em seu conjunto trazem à tona aspectos pouco revelados da vida familiar e social. O censo mais do que uma coleção de dados demográficos, permite ao historiador visitar a morada, penetrar na vida íntima, conhecer os habitantes nas suas relações de parentesco e de trabalho. Saber dos solteiros, dos casados, do número de filhos legítimos e miscigenados.

Nos testamentos e nos processos de divórcio, as descrições, por sua vez, fluem com mais facilidade. São momentos de intimidade revelados, é o filho ilegítimo reconhecido à herança nos confessados momentos de "fragilidade humana". Adultério, concubinato, rebeldia feminina e ilegitimidade mostram o outro lado da vida em família escondida na documentação oficial onde se assentam as análises 
tradicionais. A nossa pesquisa que se refere ao sul do país e especialmente a São Paulo mostrou que no iń́cio do século XIX, entre outras razões, casais se separavam alegando que os "gênios não combinavam" e mulheres provenientes de diferentes níveis sociais trouxeram situações de conflito para o casamento, provocadas por rebeldia e insatisfação.

Além disso, o fato de encontrarmos casadas as mulheres que tiveram filhos enquanto solteiras, contrapõe-se à idéia de pureza e castidade. Nesses casos, o pleno conhecimento do marido era necessário, pois poderia resiultar em anulação do matrimônio. Outras em situação idêntica, mesmo depois de viúvas contraíam segundas núpcias, o que prova que havia uma colocação social para a mulher com filhos naturais. Embora exemplos desse tipo fossem usualmente encontrados entre as camadas menos favorecidas, os nomes importantes não foram totalmente exclúfdos.

Os censos da população apontam também para a incidência da ilegitimidade. Vejamos, por exemplo, que em 1836 na cidade de São Paulo, dos 503 proprietários solteiros, 140 tinham em média até 4 filhos naturais. Sabemos, no entanto, ser impossível precisar com exatidão os filhos bastardos dos casados e as uniões de uso costumeiro. A urdidura desses contatos sociais, seus pontos de encontro, muitas vezes retratados por romancistas e historiadores, apresenta dificuldades de reconstituição na documentação da época.

Figuras do cotidiano, concubinas e mestiços aparecem como imagens fragmentadas que surgem e se escondem.

No ano de 1867, na mesma cidade de São Paulo, Jesuína Maria de São Pedro, proprietária de duas casas, dois escravos e alguns trastes e bens nos conta em testamento que fora casada com Henrique Homero de Góis "de cujo matrimônio não tive filho algum. Declaro que no meu estado de solteira antes de casar-me tive um filho de nome Jesuíno José Soares, o qual se acha em minha companhia desde seu nascimento, e por isso o reconheço como meu legítimo filho, único herdeiro de todos os meus bens, que ficarem por meu falecimento". ${ }^{40}$ Assim como esse é possível resgatar inúmeros outros depoimentos nos testamentos, escritos nos momentos em que pressões sociais e da própria família são menores. 
Numa cidade de mulheres sós, de mulheres chefes de domicillio integradas em negócios, no comércio de rua e na prostituição, as imagens por vezes se confundem e fogem do esperado e do convencional.

A presença de solteiros de ambos os sexos é significativa $(33,2 \%$ solteiros; $43,7 \%$ casados e $18,6 \%$ viúvos) e surpreende a taxa de mulheres como chefes de familia ( $63,2 \%$ homens e $36,8 \%$ mulheres), o que significa que praticamente um terço das famílias eram comandadas por mulheres que trabalhavam para a sobrevivênica e geriam negócios (por viuvez ou ausência do marido). ${ }^{41}$

Sem dúvida, esse quadro reverte muitos dos valores, atitudes e comportamentos considerados típicos da estrutura familiar brasileira do passado. Celibato, concubinato e ilegitimidade compõem uma outra triologia em que se assentavam as relações de parentesco nuançadas nesses documentos.

Ter filhos e parentes sob um mesmo teto é outra imagem típica da família brasileira. Casamentos precoces e partos sucessivos, numa vida monótona e pacata, parece ter sido o destino de muitas mulheres, segundo esse quadro. Em São Paulo, no entanto, as cenas de família são diferentes.

Em 1836, dentre 1.449 chefes de domicílios ( considerando-se aqui os solteiros, casados viúvos e divorciados) $46,4 \%$ não tinham filhos; $15,7 \%$ tinham 1 e apenas $9,8 \%$ tinham mais de 5 filhos.

Esses índices são importantes se pensarmos na família patriarcal e na relação quase indiscutível entre fertilidade e mulher brasileira, 0 que compensava inclusive a alta taxa de mortalidade infantil. Sabemos que na sociedade colonial, já que a mulher era educada para assumir os papéis de esposa e mãe, desta, quando casada, esperava-se que tivesse um filho atrás do outro. Muitos nasciam mortos ou faleciam antes de completar um ano e essa sucessão de partos contribuía sobremaneira para a decadência física da mulher e o seu envelhecimento precoce.

Neste caso, mesmo se considerarmos à alta de mortalidade infantil, o número de filhos para cada casa na cidade de São Paulo ainda é pequeno, o que contrasta com a idéia de famílias numerosas com vários integrantes. 
O contraste também é nítido se pensarmos que na maior parte das vezes os filhos casados deixavam a casa paterna, abrindo "fogo" próprio. Assim, eram poucas as familias constituídas de várias gerações com parentes colaterais, amigos e serviçais comuns nas áreas de lavoura canavieira do nordeste. As famílias extensas não dominavam, portanto, o cenário urbano do século XIX.

Por outro lado, embora seja válido afirmar que as mulheres eram principalmente educadas para assumir os papéis de esposa e mãe, isso não significa que todas tenham se casado sempre muito cedo.

Na cidade de São Paulo, por exemplo, é pequena o incidência de casais muito jovens: dos 661 casados, apenas 48 tinham menos de 20 anos, e desses, 37 ainda não tinham filhos.

Tal constatação não exclui totalmente a possibilidade de casamentos precoce, já que no censo de 1836 as idades das esposas variavam de 14 a 89 anos, e a dos maridos de 16 à 97.

No entanto, independente dos casais casarem ou não precocemente, é relevante considerarmos que predominavam nas diferentes faixas etárias as proles reduzidas. E esse é um dado real a computar.

Nesse conjunto, chama atenção também o fato de mais mulheres terem movido ações de divórcio. De 1890 à 1899 entraram na Justiça Civil, em São Paulo, 123 processos dos quais 24 foram pedidos pelos maridos, 57 pelas esposas e 42 por mútuo consentimento.

NANCY COTT constatou para Massachussts no século XVIII situação análoga, e o fenômeno parece sintomático e relevante, se considerarmos as premissas anteriormente levantadas, relativas à submissão do sexo feminino e à sua própria condição.

Os motivos que causaram tensões entre os casais, no passado, são vários e praticamente os mesmos para todo o século XIX, parecendo independer da época ou do grupo social. As argumentações, mesmo as lacônicas "e como não me foi possível viver com o dito marido, por isso dele me divorciei", apresentam limitações para o estudo do problema. Muitos depoimentos (requerente, acusado e testemunhas) são subjetivos e apontam, em certos casos, ser os mais adequados para que o processo fosse aceito pelas normas da Igreja e da sociedade, transcorrendo, portanto, com maior rapidez.

Nos processos eclesiáticos, de acordo com as Constituições Primeiras do Arcebispado da Bahia, a anulação do matrimônio 
somente era possível desde que não houvesse consumação. A separação era aceitável por motivos religiosos, alem de-outros ainda mais frequentes: adultério, sevícias, abandono do lar, injúria e doenças infecciosas. Dentre essas causas, parecem ter merecido especial atenção as que atentavam contra a moral e os costumes e a "injúria grave" estava, evidentemente, incluída nessa categoria.

$\mathrm{O}$ adultério opunha-se às noções de fidelidade, de coabitação e de ajuda mútua, princípios reguladores do casamento e do equilíbrio do ambiente familiar interno. O homem ou mulher quando adúlteros rompiam o equilíbrio e violavam a honra conjugal, praticando, portanto, em muitos aspectos, também a "injúria grave".

Indiscriminadamente, indivíduos de ambos os sexos foram acusados de "viver em adultério" nos processos referentes a São Paulo, durante todo a século passado. Isso transparece tanto na documentação relativa à Justiça Eclesiástica como na Civil, após o advento da República.

As petições eram encaminhadas aos tribunais, mesmo quando não existiam bens a separar, como um reflexo, portanto, dos valores morais e da incompatibilidade dos casais nessa situação.

Sem dúvida, esse conjunto de imagens (de celibato, de poucos filhos, de divórcio, etc.) difere em muitos aspectos do modelo típico da família brasileira.

Assim fica difícil conceber que o conceito genérico de "família patriarcal" possa ser aplicado nos diversos momentos da nossa história e para famílias dos diferentes segmentos sociais, mesmo considerando o modelo apreendido em Freyre como uma construção ideológica, constituída de traços básicos do comportamento familiar brasileiro.

No plano estrutural, a concepção de família extensa é colocada em xeque principalmente para o sul do país. É o que tem demonstrado as pesquisas mais recentes que procederam a um exaustivo levantamento de dados, comprovando a predominância do padrão nuclear de família. Tudo nos leva a concluir que o panorama se repete para outras áreas, mesmo se considerarmos aquelas ainda não pesquisadas.

Ao nosso ver, tal constatação não invalida a concepção de família patriarcal usada por Gilberto Freyre para caracterizar as áreas de lavoura canavieira do nordeste. São traços, persistências de atitudes, comportamentos e valores que viajando através do sangue e do tempo 
deixaram marcas profundas na sociedade. É evidente, no entanto, que perde a eficácia quando considerado como parâmetro único da família brasileira.

Por outro lado é importante o pesquisador da famflia ter presente que as relações familiares devem constituir terreno onde o historiador penetra com cuidado, pois as relações que se estabelecem no dia-a-dia da população são complexas e nem sempre estão inseridas em sistemas ideológicos e de moral que servem de controle da ordem social estabelecida.

\section{NOTAS E REFERÊNCIAS BIBLIOGRÁFICAS}

1 São inúmeras e seria impossível arrolá-las de uma só vez. Entre elas podemos citar: DAVIS, Natalie Zenon. Society and the sexes in early Modern Europe - $15_{\text {th }}$ to $18_{\text {th }}$ Centuries - a bibliography. Berkeley: University of California, 1973; MULHER Brasileira, bibliografia anotada 1 e 2. São Paulo: Brasiliense/ Fundação Carlos Chagas, 1981; BRESCIANI, Maria Stela (org.). A mulher no espaço público. Revista Brasileira de História. $\mathrm{n}^{\circ}$ 18. São Paulo: ANPUH/ Marco Zero, 1989.

2 PERROT, Michelle. Os excluídos da História. Rio de Janeiro: Paz e Terra, 1988. p. 168.

3 Ver BOXER, C. R. A mulher na expansão ultramarina ibérica. Lisboa: Livros Horizonte, 1977.

4 ROGERS, Susan. Female forms of power and the mith of male dominance. American Ethnologist. vol. 2. no 4, nov. 1975; PERROT, Michele, op. cit.

5 Ver METCALF, Alida. "Mulheres e propriedade: filhas, esposas e viúvas em Santana de Parnaíba no século XVIII". Revista da SBPH. São Paulo, no 5, 1989/90. 
6 BOXER, C. R. op. cit.

7 SAMARA, Eni de Mesquita. A familia brasileira. $3^{\mathrm{a}}$ ed. São Paulo: Brasiliense, 1986 e As mulheres, o poder e a familia - São Paulo, século XIX. São Paulo: Marco Zero/ Secretária Estadual da Cultura de São Paulo, 1989.

8 RUSSEL-WOOD, A.J.R. "Women and society in colonial Brazil”. Journal of Latin-American Studies. $n^{\circ}$ 9, I.

9 Ver KUZNESOF, Elizabeth. "The role of the female-headed household in Brazilian Modernization: 1765-1836". Journal of Social History, 13 (1980): 586-613; DIAS, Maria Odila Leite da Silva. Quotidiano e poder em São Paulo - século XIX. São Paulo: Brasiliense, 1984; SAMARA, Eni de Mesquita. As mulheres, o poder e a familia. op. cit.

10 Sobre a educação feminina no período colonial ver SILVA, Maria Beatriz Nizza da. "Educação feminina e educação masculina no Brasil Colonial". Revista de História. 109: 149-164. 1977.

11 GRAHAM, Sandra Lauderdale. House and street: the domestic world of servants and masters in XIX $X_{t h}$ century Rio de Janeiro. Cambridge Univerity Press, 1988.

12 PERROT, Michelle. op. cit.

13 dem. p. 178.

14 DIAS, Maria Odila Leite da Silva. op. cit.

15 SAMARA, Eni de Mesquita. A familia brasileira. op. cit.

16 DIAS, Maria Odila Leite da Silva. op. cit.

17 SOUZA, Antonio Cândido de Mello e. The Brazilian Family. New York: Marchand General, 1951. 
18 Idem.

19 DIAS, Maria Odila Leite da Silva. op. cit. p. 8.

20 Ver SAFFIOTI, Heleieth. A mulher na sociedade de classes: mito e realidade. Petrópolis: Vozes. 1976; e também O poder do macho. São Paulo: Moderna, 1987.

21 STEVENS, Evelyn. "Marianismo: the other face of machismo in Latin America". In: PESCATELLO, Ann (ed.). Female and male in Latin America. University of Pittsburg Press, 1973.

22 LAVRIN, Asunción. Latin American Women. Westport: Greenwood Press, 1978.

23 HAHNER, June. "The $\mathrm{XIX}_{\text {th }}$ century feminist press and women's rights in Brazil". In: LAVRIN, Asunción (ed.). op. cit.

24 PESCATELLO, Ann (ed.). Female and male... op. cit.

25 JAQUETTE, Jane S. Literary archetypes and female role alternatives: the woman and novel in Latin America; FLORA, Cornélia Butler. The passive female and social change: a crosscultural comparation of women's magazine fiction; PESCATELLO, Ann. "The brazileira:...". In: PESCATELLO, Ann. (ed.). op. cit.

26 HENDERSON, James D. \& HENDERSON, Linda Roddy. Ten notable women of Latin America. Chicago: 1978. A respeito dos relatos de viajantes ver LEITE, Miriam Moreira. "Mulheres e famílias". In: SAMARA, Eni de Mesquita (org.). Familia e grupos de convivio - Revista Brasileira de Historia. São Paulo: ANPUH/ Marco Zero, nº 17, 1989.

27 Ver a respeito Journal of Interamerican Studies and World Affairs. vol. 17, novembro 1975.

28 METCALF,Alida. "Mulheres e propriedades... op. cit. 
29 Sobre o dote ver NAZZARI, Muriel. "Dotes paulistas: composição e transformações (1600-1870)". Revista Brasileirá de História. São Paulo: ANPUH/ Marco Zero, nº 17, 1989; LAVRIN, Asunción e COUTURIER, Edith. "Dowries and wills, -a view of women's socio-economic role in Guadalajara and Puebla, 1640-1790". HARH. 59 (2): 280-304, 1979 e SAMARA, Eni de Mesquita. "O dote na sociedade paulista: legislação e evidências". Anais do Museu Paulista. São Paulo, tomo XXX, 1980/81.

30 SAFIOTTI, Heleieth. O poder do macho. op. cit.

31 FREYRE, Gilberto. Casa-grande e senzala. 10 ${ }^{\text {a }}$ ed., Rio de Janeiro: José Olympio. 1977. 2 vols.

32 Ver SAMARA, Eni de Mesquita. op. cit.

33 A esse respeito ver DIAS, Maria Odila Leite da Silva. op. cit. e PERROT, Michelle. op. cit.

34 A esse respeito ver SAMARA, Eni de Mesquita. "A história da família no Brasil". In: Familia e grupos de convtvio. Revista Brasileira de História. São Paulo: ANPUH/ Marco Zero, nº 17, 1989. pp. 7-36.

35 Nos últimos dez anos foram organizados inúmeros encontros, seminários e debates sobre 0 assunto nas diversas áreas do conhecimento. Lembro também em 1985 a criação do "Seminário de Estudos sobre a Família e a População no Passado Brasileiro", patrocinado pela ANPUH/ FIPE que realizou vários encontros e publicou 37 textos avulsos.

36 A esse respeito ver COSTA, Iraci e SAMARA, Eni de Mesquita. Demografia histórica, bibliografia brasileira. São Paulo: IPE/USP, 1984.

37 São inúmeras as pesquisas sobre a família escrava no Brasil, presentes especialmente nos números recentes da Revista Estudos Econômicos e na Revista Brasileira de História. 
38 SAMARA, Eni de Mesquita. As mulheres, o poder e a familia. São Paulo: Marco Zero/ Secretaria de Estado da Cultura, 1989 e a $A$ familia brasileira. $3^{\text {a }}$ ed. , São Paulo: Brasiliense, 1987.

39 FREYRE, Gilberto. Casa-grande e senzala. $9^{a}$ ed., Rio de Janeiro: José Olympio, 1977.2 vols. e Sobrados e mocambos. $5^{\text {a }}$ ed., Rio de Janeiro: José Olympio, 1977.

\section{TESTAMENTOS, 1867}

41 A esse respeito ver DIAS, Maria Odila Leite da Silva. Quotidiano e poder em São Paulo, século XIX. São Paulo: Brasiliense, 1984.

\section{BIBLIOGRAFIA}

BOXER, C.R. A mulher na expansão ultramarina ibérica. Lisboa: Livros Horizonte, 1977.

BRESCIANI, Maria Stela (org.) A mulher no espaço público. Revista Brasileira de História. $\mathrm{n}^{0}$ 18. São Paulo: ANPUH/ Marco Zero, 1989.

DAVIS, Natalie Zenon. Society and the sexes in early Modern Europe

$-15_{\text {th }}$ to $18_{\text {th }}$ centuries - a bibliography. Berkeley: University of California, 1973.

DIAS, Maria Odila Leite da Silva. Quotidiano e poder em São Paulo - século XIX. São Paulo: Brasiliense, 1984.

FLORA, Cornélia Butler. "The passive female and social change: a cross-cultural comparation of women"s magazine fiction". In: PESCATELLO, Ann (ed.). Female and male in Latin America. University of Pittsburg Press, 1973.

FREYRE, Gilberto. Casa-grande e senzala. $10^{\mathrm{a}}$ ed., Rio de Janeiro: José Olympio, 1977. 2 vols.

GRAHAM, Sandra Lauderdale. House and street: the domestic world of servants in XIX ${ }_{t h}$ century Rio de Janeiro. Cambridge University Press, 1988. 
HAHNER, June. "The XIX ${ }_{\text {bh }}$ century feminist press and women's rights in Brazil". In: LAVRIN, Asunción (ed.). LAVRIN, Asunción. Latin American Women. Westport: Greenwood Press, 1978.

HENDERSON, James D. \& HENDERSON, Linda Roddy. Ten notable women of Latin America. Chicago, 1978.

JAQUETTE, Jane S. "Literary archetypes and female role alternatives: the woman and the novel in Latin America". In: PESCATELLO, Ann (ed.). Female and male in Latin America. University of Pittsburg Press, 1973.

JOURNAL OF INTERAMERICAN STUDIES AND WORLD AFFAIRS. vol. 17, novembro 1975.

KUZNESOF, Elizabeth. "The role of the female-headed household in Brazilian Modernization: 1765-1836. Journal of Social History, 13 (1980): 586-613.

LAVRIN, Asunción e COUTURIER, Edith. "Dowries and wills, a view of women's socio-economic role in Guadalajara e Puebla, 1640-1790". HAHR. 59 (2): 280-304, 1979.

LAVRIN, Asunción. Latin American women. Westport: Greenwood Press, 1978.

LEITE, Miriam Moreira, "Mulheres e Famílias". In SAMARA, Eni de Mesquita (org.) Familia e grupos de convívio - Revista brasileira de História. São Paulo: ANPUH/ Marco Zero, $\mathrm{n}^{0}$ 17, 1989.

METCALF, Alida. "Mulheres e propriedade: filhas, esposas e viúvas em Santana de Parnaŕba no século XVIII". Revista da SBPH. São Paulo, no 5, 1989/90.

MULHER Brasileira, bibliografia anotada 1 e 2. São Paulo: Brasiliense/ Fundação Carlos Chagas, 1981.

NAZZARI, Muriel. "Dotes paulistas: composição e transformações (1600-1870)". Revista brasileira de História. São Paulo: ANPUH/ Marco Zero, nº 17, 1989.

PERROT, Michelle. Os exclutdos da Historia. Rio de Janeiro: Paz e terra, 1988.

PESCATELLO, Ann. "The brazileira: images and realities in writings of Machado de Assis and Jorge Amado". In PESCATELLO, Ann 
(ed.). Female and male Latin America. University of Pittsburg Press, 1973.

ROGERS, Susan. Female forms of power and the mith of male dominance. American Ethnologist. vol. 2 n $^{\circ}$ 4, nov. 1975.

RUSSEL-WOOD, A.J.R. "Women and society in Colonial Brazil". Journal of Latin-American Studies. $\mathrm{n}^{\circ}$ 9, I.

SAFFIOTI, Heleieth. A mulher na sociedade de classes: mito $e$ realidade. Petrópolis: Vozes, 1976.

SAFFIOTI, Heleieth. O poder do macho. São Paulo: Moderna, 1987. SAMARA, Eni de Mesquita. "O dote na sociedade paulista: legislação e evidências". Anais do Museu Paulista. São Paulo, tomo XXX, 1980/81.

SAMARA, Eni de Mesquita. A família brasileira . $3^{\text {a }}$ ed., São Paulo: Brasiliense, 1986.

SAMARA, Eni de Mesquita. As mulheres, o poder e a familia - São Paulo, século XIX. São Paulo: Marco Zero/ Secretária Estadual da Cultura de São Paulo, 1989.

SILVA, Maria Beatriz Nizza da. "Educação feminina e educação masculina no Brasil Colonial". Revista de História. 109: 149164, 1977.

SOUZA, Antonio Candido de Mello e. The Brazilian Family, New York: Marchand General, 1951.

STEVENS, Evelyn. "Marianismo: the other face of machismo in Latin America". In PESCATELLO, Ann (ed.). Female and male in Latin America. University of Pittsburg Press, 1973. 